\title{
The role of Internet in the development of future software projects
}

\author{
M.R. Martínez-Torres, S.L. Toral, F. Barrero and F. Cortés \\ University of Seville, Seville, Spain
}

\begin{abstract}
Purpose - The Internet has evolved, prompted in part by new Web 2.0 technologies, to become a more widespread platform for interaction, communication, and activism. Virtual communities, or groups of people informally bound together by shared expertise, synthesise this Internet evolution and the Web 2.0 technology. Users increasingly want to engage online with one another and with organisations of all kinds. These novel Internet-based technologies dominate the new business models of the digital economy giving companies radical new ways to harvest the talents of innovators working outside corporate boundaries. One of the most illustrative examples of this new trend is the Open Source Software (OSS) projects development. This paper aims to analyse the structure and topology of the virtual community supporting one of the most successfully OSS projects, Linux. The objective is to provide conclusions for being successful in the development of future virtual communities. As companies learn to manage these virtual communities, they will develop smarter and faster ways to create value through them.

Design/methodology/approach - The interactions of the virtual community members of an ARM-embedded Linux project website is analysed through social network analysis techniques. The participants' activity is studied and some conclusions about the participation features are obtained using the Gini coefficient. In particular, a participation inequality behaviour or a concentration on a small number of developers is clearly observed.

Findings - The paper deals with the guidelines that virtual communities should follow to be successful. Results about the structure of a successful virtual community and its time evolution are provided to determine the mentioned guidelines.

Research limitations/implications - The research is limited to a particular virtual community engaged with the development of the ARM-embedded Linux OSS. Other successful virtual communities can be analysed, and the conclusions could be compared. Anyway, the proposed analysis methodology can be extended to other virtual communities.

Originality/value - The paper fulfils the development and features of Internet virtual communities to be successful. Results have important implications over the development of new software business models based on virtual communities and open source software. Contributions about the best organisation of virtual communities leading to a successful development of the underlying project are presented.
\end{abstract}

Keywords Communities, Internet, Social networks, Computer software, Information transfer

Paper type Research paper

\section{Introduction}

The advent of Web 2.0 is driving an emergent interest in the so-called virtual communities of practice. The current web is a much different entity than the web of a decade ago. Until recently, the web has been far from interactive and users rarely had a

The authors gratefully acknowledge support provided by the Spanish Ministry of Education and Science within the I + D + I national project with reference DPI2007-60128, and the Consejería de Innovación, Ciencia y Empresa (Research Project with reference P07-TIC-02621). 
chance to participate (Kolbitsch and Maurer, 2006). But now the social-networking trend is causing a major shift from publisher-generated content, where one or a few publishers decide on what information is published on a website, to user-generated content, where the majority of the visitors decide on the information that is published on a website. The model has basically changed from top-down to bottom-up creation of information and interaction, and this has been made possible thanks to a new generation of web applications that give power to users (Weaver and Morrison, 2008). Internet is causing the emergence and the consolidation of new social structures and forms of organisations in which the traditional temporary space references are not valid. These social structures, which take place in a cybernetic virtual space, help people to communicate themselves supporting a level of interaction that extends in time, and they are usually known as virtual communities. These kind of social structures are not new. They are well known since two decades ago, when the term "community of practice" was first introduced by Lave et al. (1991). The idea of a community of practice implies a group of people in contact with one another involved in a circumscribed set of activities and a shared practice (Fox, 2000). They develop their own routines, formal and informal "rules", and practices evolve as a result of learning (Wenger, 1998). The importance of these communities has been acknowledged in a number of previous works (Brown and Duguid, 1998; Boland and Tenkasi, 1995; Pan and Leidner, 2003), showing their relation with knowledge management (Wenger et al., 2002; Martínez-Torres, 2006). When their participants keep in contact by means of electronic tools, they are considered virtual communities.

Virtual communities are recognised as a new business model of the digital economy (Lin, 2007; Figallo, 1998; Toral et al., 2009a), characterised by two architectural features:

(1) The members of the community contribute to the creation of economic value often on an equal basis - as peers (Timmers, 1998).

(2) Transactions and their social environment are linked such that the social environment contributes to the value creation (Hummel and Lechner, 2002).

This is the case of OSS, which represents a new and revolutionary way to develop software (Moody, 2001; Raymond, 1999). OSS projects are based on virtual communities of support, responsible of the development of the project (Lee and Cole, 2003). In the software industry, the OSS development approach has helped produce reliable, high quality software quickly and inexpensively (Mockus et al., 2000). The community represents an inexhaustible resource and drives the development of the underlying software in accordance with their necessities. But another consequence of the advent of open source software is that software prices have drove down motivating a change in the software business model. Traditional product sales and license fees have declined, and product company revenues have shifted to services such as annual maintenance payments that entitle users to patches, minor upgrades, and often technical support (Cusumano, 2008). In this context, software companies are becoming to be interested in promoting virtual communities around their software production to concentrate their efforts on services more than on programming. Nevertheless, virtual communities require some structure to evolve satisfactorily. The purpose of this paper consists of analysing the structure of virtual communities leading to successful underlying software and their evolution. The obtained results confirm the necessity of planning the virtual 
community. The rest of the paper is organised as follows. The next section is a review of virtual communities in OSS projects and the participation as the basic underlying mechanism of interaction. After that, the case study based on ARM Linux is presented as well as the methodology to be used. The one after that discusses the results and implications of the empirical analysis and the final section discusses conclusions for practice and research.

\section{Virtual communities in OSS projects}

In OSS model of software development, the source code is available for programmers to view, read, modify and re-distribute without the property right restrictions of proprietary software (Waring and Maddocks, 2005). OSS development not only exemplifies a viable software development approach, but also a model for the creation of self-learning and self-organising communities. The importance of the community of an open source project lies not only in the development of the project but also in the performance of the testing and providing quality feedback. Proprietary vendors use financial resources to put the software through extensive testing and quality assurance. In contrast, Open Source projects have the community as a resource (Gruber and Henkel, 2006; Lakhani and Hippel, 2003). The user community of an open source project consists of the people that use the software and participate in some way. Enabled by the Internet and Web 2.0 technologies, geographically distributed individuals voluntarily contribute to a project by means of the Bazaar model (Raymond, 1999; Sowe et al., 2006). They come from a wide variety of backgrounds, including educational institutions, companies, governments and individuals. In general, an Open Source community is very difficult to analyse as it is an abstract social phenomenon. Fortunately, OSS projects can be observed and analysed due to their presence on the Internet, and their publicly available communication.

The process underlying the development of the community is the legitimate peripheral participation (LPP) (Lave et al., 1991). LPP is the process by which individuals learn how to function as a community member through participation in the community, enabling them to acquire the language, values, and norms of the community. Learning is gradually achieved as an individual moves from being a novice, gaining access to community practices, to complete socialisation and therefore becoming an insider or full member of the community (Wenger, 1998). As individuals participate and earn their status in the community through conducting their work, they construct and reconstruct their social identity in relation to the community (Shang et al., 2006). In this manner, the legitimisation process of a community of practice differs from the legitimisation gained through hierarchical status in more formal groupings such as a team.

It is clear that the major productive assets of OSS projects are developers, who interact with other developers forming a small but well organised community to intensify the learning interactions that matter most of the OSS developments (Hertel et al., 2003). Although there are tens of thousands of developers available, some authors claim that much of the software development is done by a small percentage of individuals (Madey et al., 2004; Kuk, 2006). Such concentration, also called participation inequality, can be explained by the different user profiles of virtual communities. Participation inequality is in stark contrast with the fully participative "bazaar" imagery of OSS development proposed by Raymond (1999). The bazaar style of design imagines the development of software as a flea market of loosely coordinated 
programmers and users who collectively work on designing, implementing, and testing new computer code (Arakji and Lang, 2007).

In this paper, one of the most successful virtual communities in the development of an OSS project is analysed. In particular, some results about its structure and performance are obtained with the purpose of extending these conclusions to other virtual communities.

\section{Case study: ARM embedded Linux}

Linux is a PC-based operating system that has been developed as open source software along the structure of the UNIX operating system. The Linux system consists of a large number of programs or modules that are arranged around a kernel. The task of the kernel is to give the programs access to resources such as hard disk storage, random access memory, network band width, etc. The central role of the kernel makes it an essential part of the Linux operating system, currently containing about two million lines of source code (Bovet and Cesati, 2001). As a difference to desktop Linux, the term embedded Linux denotes variants of the Linux operating system that are tailored to embedded devices. The importance of embedded systems in the next future has been recently highlighted (ARTEMIS Strategic Research Agenda Working Group, 2006; Toral et al., 2005, 2007; Barrero et al., 2008). Intelligent functions embedded in components and devices will be a key factor in revolutionising industrial production processes, from design to manufacturing and distribution, particularly in the traditional sectors. The increase of the share of the value of embedded electronics components in the value of the final product is expected to grow significantly in the next five years. Although a multitude of embedded operating systems are currently available (Wind River's VxWorks, Microsoft Windows CE, QNX Neutrino, etc), Linux is firmly in first place as the operating system of choice for smart gadgets and embedded systems (Henkel, 2006). Nevertheless, embedded Linux shows significant differences from conventional desktop Linux. First, embedded systems incorporate a wider variety of input/output devices than typical desktop computers. That means that embedded systems programmer often has to deal directly with the hardware. Second, in contrast to other typical open source projects, most contributions in this field do not come from volunteers or hobbyists, but from commercial firms or researchers, many of which are dedicated embedded Linux projects. Third, the fact that it comes under an OSS license like GPL (GNU General Public License) makes firms consider revealing their own developments, as opposite to the case of proprietary software. Finally, although embedded devices are becoming more and more ubiquitous, the heterogeneity of embedded devices forces to adapt the operating system to the specific device. Sometimes, drivers for specific peripherals are not available or they do not support the whole functionality of these peripherals. So a huge work of customisation of the open source operating system must be performed. All these features encourage the collaborative development and justify the necessity of studying the behaviour of the community.

ARM, which stands for Advanced RISC Machine, is a family of processors maintained and promoted by ARM Holdings Ltd. Contrary to other chip manufacturers such as IBM, Motorola, and Intel, ARM Holdings does not manufacture its own processors. Instead, ARM designs the CPU cores for its customers based on the ARM core, charges customers licensing fees on the design, and lets them manufacture the chip wherever they see fit. Although there does not seem to be a central producer of ARM 
chips on the market, all ARM processors share the same ARM instruction set, which makes all variants fully software compatible. Presently, ARM Linux port has been implemented in more than 1,200 related boards, and it is supported by a projects' website at www.arm.linux.org.uk/. Particularly, the "lists.arm.linux.org.uk" mailing list is one of the highest quality and most effective forum for finding answers to problems when working with ARM embedded Linux (Yaghmour, 2003). In general, mailing list data of open source projects are widely available and easy to extract, providing an excellent infrastructure to study community participation in an OSS project. According to several studies (Te'eni and Schwartz, 1999; Schwartz and Te'eni, 2000), e-mail communication in a modern organisation is over 78 per cent action-oriented, and represents the foundation for most organisational action. Data from ARM Linux mailing list located at "lists.arm.linux.org.uk" during the years 2001 to 2006 have been used in this research. A total of 12,010 messages posted by 2,086 authors have been considered. Basically, mailing list archives can be sorted by messages, authors and threads of discussion. A thread is given by responses to an initial e-mail, covering a specific subject. Threads will be considered the basic unit of our analysis, as it is the mechanism through which interactions take place (Jones et al., 2004). The use of discussion threads as the basic unit of analysis is highly valid, considering that the epistemic interactions in support of OSS development often take place in discussion threads where individual postings provide the context to encourage participation (Kuk, 2006).

\subsection{Data preparation and methodology}

Data were collected from the ARM Linux mailing list. This web page contains links to archived mailing lists corresponding to each month from January 2000 to date. As year 2000 is not complete (this was the first year in which the project was launched), we have started our analysis on January 2001. The data extraction and processing were conducted using MATLAB. A program in MATLAB was developed for the automatic reading at a URL into a string. Next, threads and authors were extracted processing the stored strings. Basically, a social network is formed by nodes and ties among these nodes. In this case, community nodes are those authors who reply messages in a thread and the corresponding ties are the links between an author answering a question to the rest of authors who have previously posted messages in this thread. In contrast to a reply to a single message, it is more cognitively complex to reply to a threaded discussion, as their responses have to be coherently developed to take account of the ebb and flow of earlier postings (Knock, 2001). That is the reason why an author posting to a thread is tied to all the authors who have previously posted to the same thread.

When accounting authors, it is necessary to consider the fact that they are identified using aliases. Aliases usually correspond to a unique e-mail address, but this is not always truth. Header of messages should then be processed to check there is no duplicity of aliases or e-mails (Bird et al., 2006).

Both authors' participation and thread analysis constitute the basis for mailing list analysis. The Gini coefficient was used to provide a measure of the level of participation based on the numbers of postings made by individual developers within a mailing list (Gini, 1936; Dixon et al., 1987). The Gini coefficient has a value ranging from 0 to 1: with "too little" concentration (i.e. all developers posted fairly evenly), the Gini coefficient approaches 0; and with "too much" concentration (i.e. a very few developers actively engaged in posting), the Gini coefficient approaches 1. Mathematically, the Gini 
coefficient (or Gini ratio) is a summary statistic of the Lorenz curve, which is a function of the cumulative proportion of ordered individuals mapped onto the corresponding cumulative proportion of their size. Given a sample of $n$ ordered individuals with $x_{i}^{\prime}$ the size of individual $i$ and $x_{1}^{\prime}<x_{2}^{\prime}<\ldots<x_{n}^{\prime}$, then the sample Lorenz curve is the polygon joining the points $\left(h / n, L_{h} / L_{n}\right)$, where $h=0,1,2, \ldots, n, L_{0}=0$, and $L_{h}=\sum_{i=1}^{h} x_{i}^{\prime}$. Alternatively, the Lorenz curve can be expressed as:

$$
L(y)=\frac{\int_{0}^{y} x d F(x)}{\mu}
$$

where $F(x)$ is the cumulative distribution function of ordered individuals and $\mu$ is the average size. If all individuals are the same size, the Lorenz curve is a straight diagonal line, called the line of equality. If there is any inequality in size, then the Lorenz curve falls below the line of equality. The Gini coefficient is the ratio between the area enclosed by the line of equality and the Lorenz curve, and the total triangular area under the line of equality. Operationally, the Gini coefficient is more easily calculated from unordered size data as the "relative mean difference", i.e. the mean of the difference between every possible pair of individuals, divided by the mean size $\mu$ :

$$
G=\frac{\sum_{i=1}^{n} \sum_{j=1}^{n}\left|x_{i}-x_{j}\right|}{2 n^{2} \mu}
$$

Finally, social networks will be visualised using NetDraw (Borgatti, 2002).

\section{Results}

The Gini coeffcient was calculated for the case study during the period 2001-2006 to illustrate the different user profiles of virtual communities. The result of 0.684 obtained from Figure 1 clearly proves the existence of a core of regular contributors inside the community. They are responsible for the majority of contributions. As a difference, free riders can be defined as "members who enjoy the benefits of the collective good without contributing to its establishment" (Millen et al., 2005). They usually post questions but they are nor involved in the development of the community. They are tolerated because they are an important resource. As time goes by, some users begin to take interest in the project and voice their opinion, becoming contributors. Figure 2 details the distribution of regular contributors versus free riders. Contributors are the coloured vertices while free riders are shown in white. Notice that white vertices are placed on the periphery of the community while regular contributors are placed inside the community in more or less central positions depending on their activity (Borgatti and Everett, 1999).

Table I details the general data of the ARM linux mailing list for the considered period 2001-2006. The column of authors accounts for the number of people who has posted messages to the mailing list each year. Not all of them can be considered as contributors. Contributors are defined as the nodes of the social network, that is, people who has posted at least one answer to a previously posted question. They have been defined as the community nodes. But just a small fraction of them can be considered regular contributors. In the study, regular contributors are defined as users who has posted at least five answers to some other author of the list. They are called insider 
Figure 1.

Gini coefficient for ARM

Linux port mailing list (0.684)
Regular contributors vs free riders
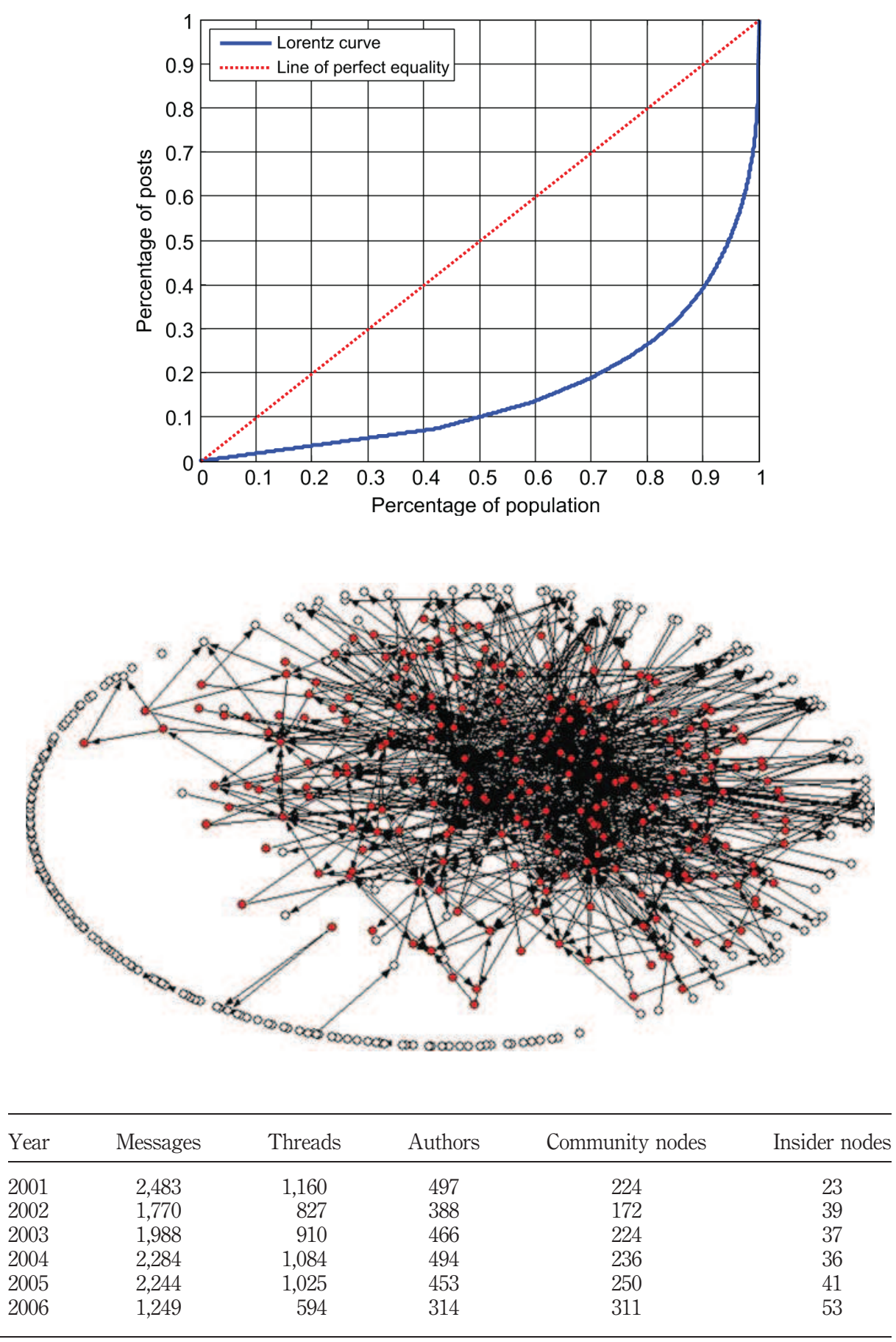

\begin{tabular}{lcrccc}
\hline Year & Messages & Threads & Authors & Community nodes & Insider nodes \\
\hline 2001 & 2,483 & 1,160 & 497 & 224 & 23 \\
2002 & 1,770 & 827 & 388 & 172 & 39 \\
2003 & 1,988 & 910 & 466 & 224 & 37 \\
2004 & 2,284 & 1,084 & 494 & 236 & 46 \\
2005 & 2,244 & 1,025 & 453 & 250 & 53 \\
2006 & 1,249 & 594 & 314 & 311 & \\
\end{tabular}

Table I.

General data of the studied mailing list during the period 2001-2006 
nodes, constitute the core of the community, and represent around 10-23 per cent of the community.

The process of becoming an insider contributor requires the learner to learn the ways of the community, and how they interact. By participating, the learner observes the practice of the other members of the community and tests different strategies or ways of interacting with them. In the course of this process, the learner begins to form his own impression of the inner workings of the community. Completion of this process and transformation of the learner into an insider requires that the insider must allow the learner legitimate peripheral participation.

Figures 3-6 illustrate the evolution of the core of the studied community. They have been visualised using the NetDraw social network analysis tool. The red circles represent insider nodes, while the lines identify the ties to other authors. The direction of the arrow indicates the knowledge flow. Notice that each tie means at least five answers to some author.

During the first year, 2001, the community exhibits a clear star structure centralised by the moderator of the list (Figure 3). According to Table I, the number of insiders is the minimum of the community lifetime. Notice this is the first year of project, therefore peripheral contributors are still learning and it is too early to become an insider.

During the second year, Figure 4, the structure of the community's core is changing. Although the role of the moderator is still essential, some sub groups have emerged. New threads have been developed without the explicit participation of the moderator, and the number of insiders has increased.

After two years, the community had achieved a stable situation. The structure for years 2003 and 2006 are shown in Figures 5 and 6, respectively. Respect to the previous years, the number of subgroups has increased, and the resulting structure is divided in different areas with their own experts. Years 2004 and 2005 have been omitted because they exhibit a similar behaviour. In general, the number of insiders is growing, reaching the maximum value in 2006 .

The obtained results led to the following conclusions:

- The number of community and insider nodes shows an upward trend, which is independent of the total number of messages and threads. This fact suggests that a successful an OSS project requires professional core contributors, in accordance with other studies (Healy and Schussman, 2003).

- On the other hand, the analysed evolution suggests that the core of the community tends to branch out if the social network is working properly. Several sub groups arise, and discussions are supported by experts in different fields. As a consequence, successful OSS projects will tend to have a strong hierarchical component, at least in the ways they manage the relations between the core developers and other contributors.

These general conclusions should be taken into account when designing virtual communities supporting software projects. The organisation and evolution of the community (which are behind the successful or unsuccessful development of the underlying OSS project), and the advent of free and open source software (which drove down software prices) are changing the paradigm of the software business. Traditional product sales and license fees have declined, and product company revenues have shifted to services such as annual maintenance payments that entitle users to patches, 


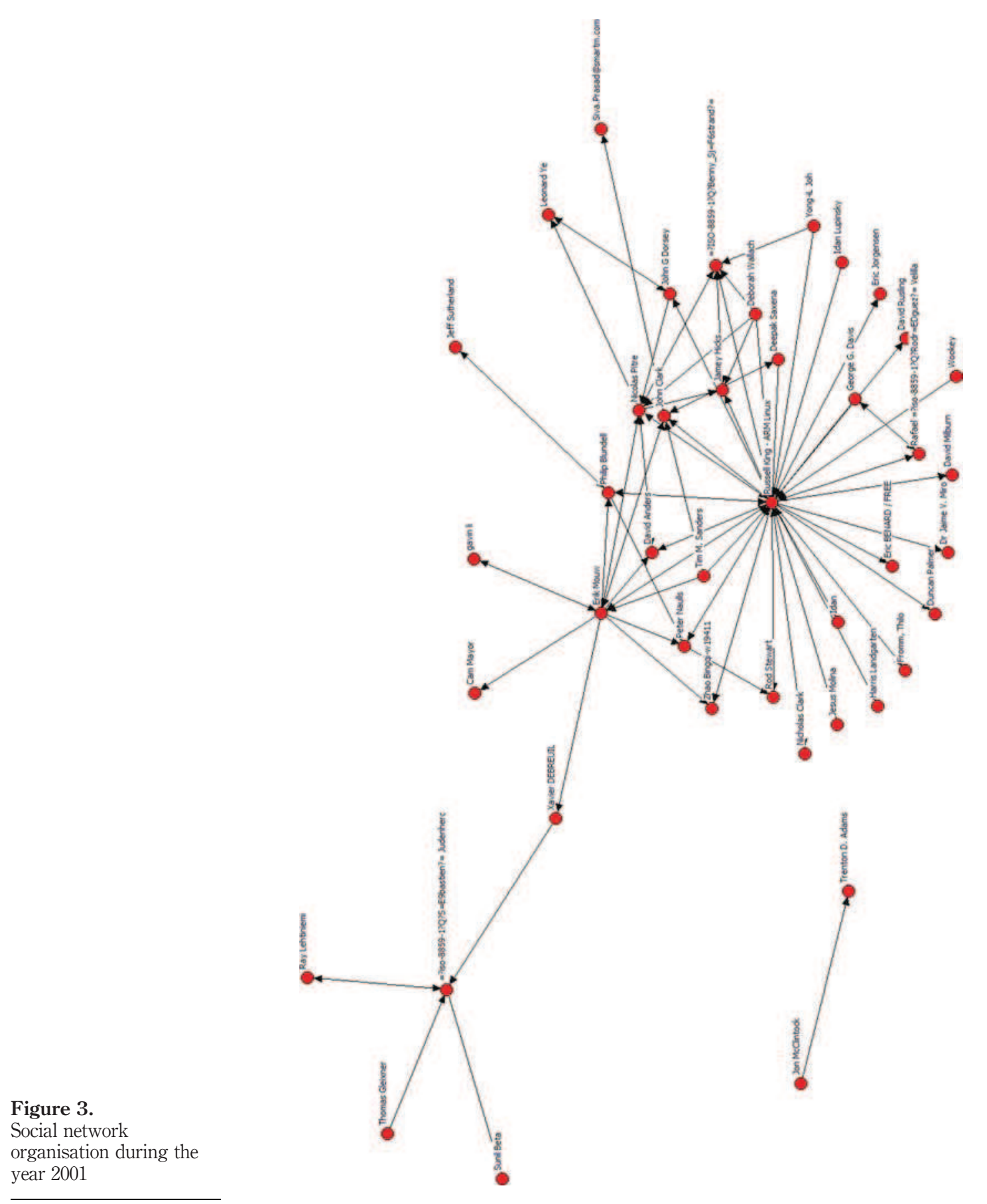




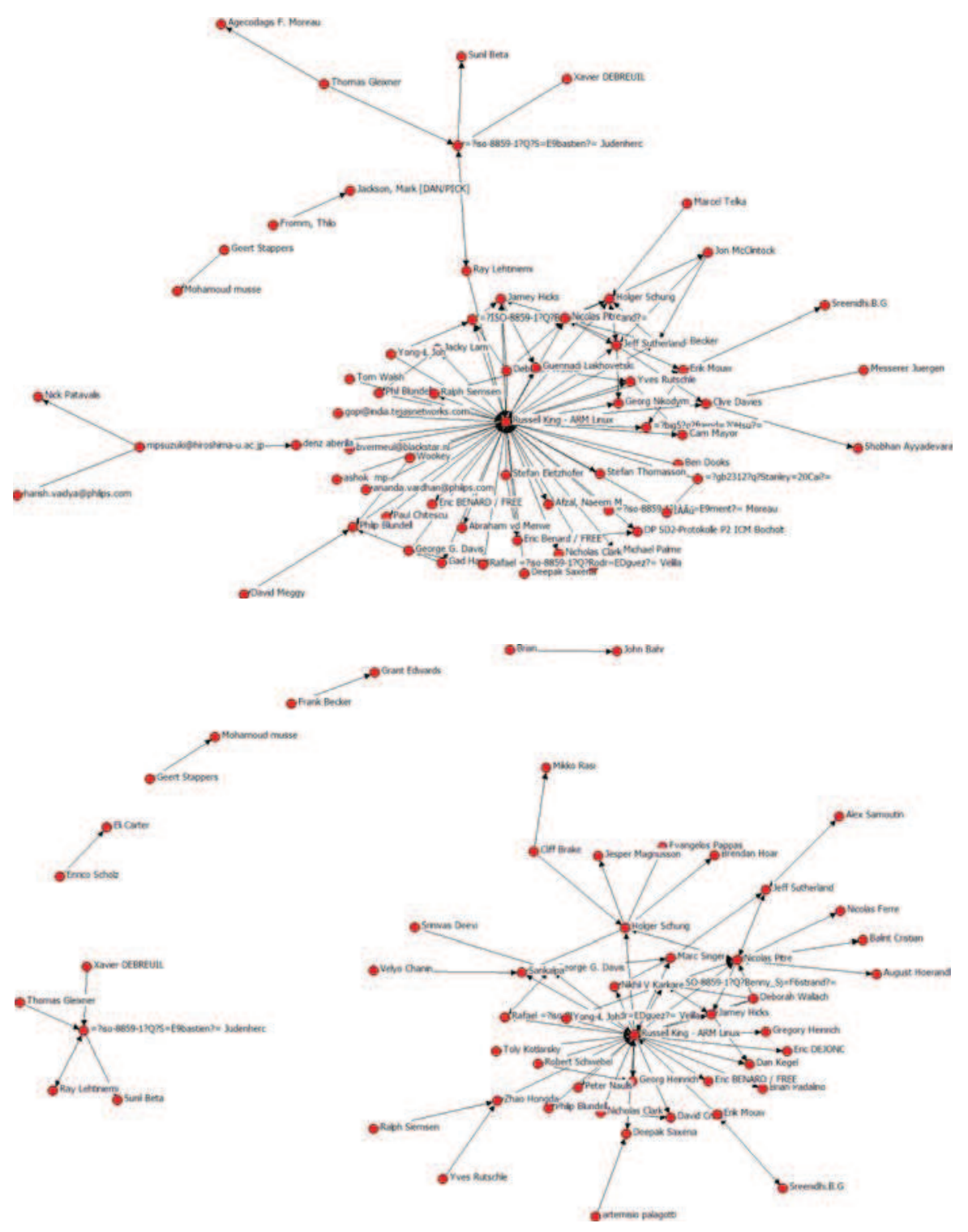

Figure 4.

Social network organisation during the year 2002

Figure 5. Social network organisation during the year 2003

minor upgrades, and often technical support (Cusumano, 2008). Moreover, many critical enterprise components are available as free and open source software. In other words, software now is also commoditised just like hardware, and as a consequence prices will fall to zero or near zero for any kind of standardised product (Cusumano, 2008). In this scenario, free or open source software represents an emergent trend and their successful development will be conditioned by the structure of the virtual community of support. 
Figure 6.

Social network organisation during the year 2006

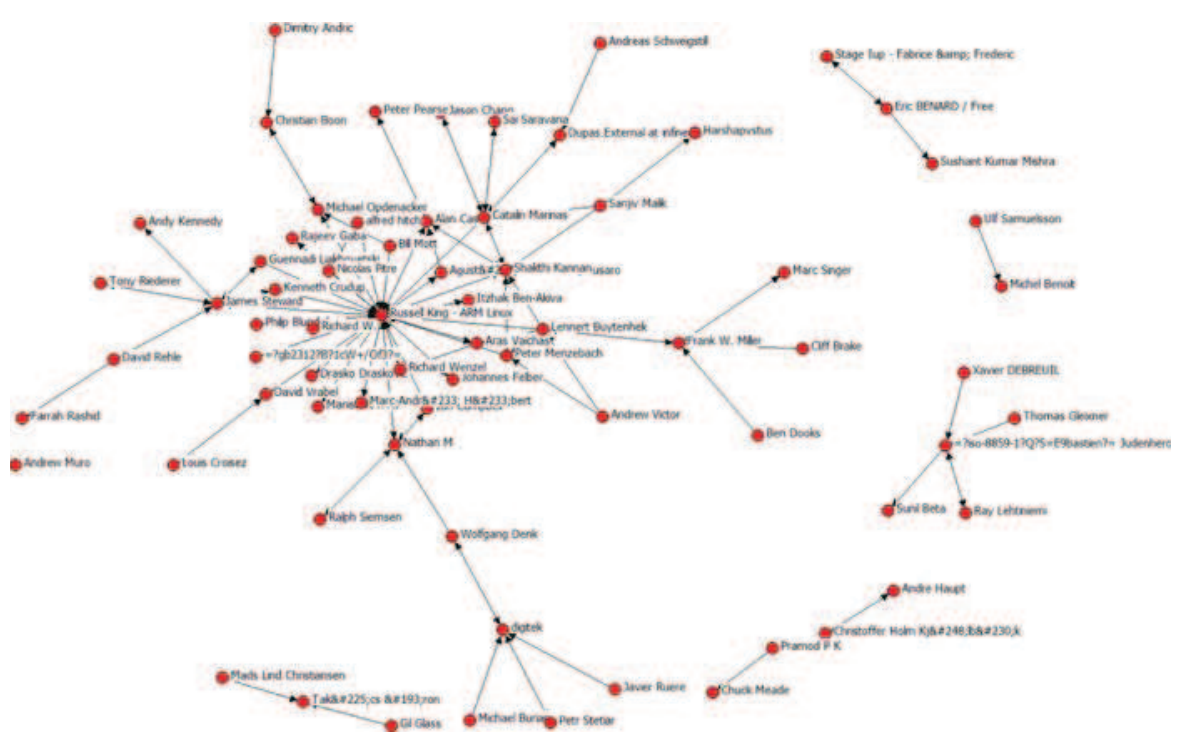

5. Managerial implications

The OSS has become widespread over the last decade, and today both open and closed software coexist. The future will tell us whether the software industry will move towards OSS development processes, but in any case, the interest among firms about the open source paradigm is clear. There are several ways in which firms can extract profits from their engagement in OSS (Dahlander, 2005; Deek and McHugh, 2008). Dual licensing lets the owner of a copyrighted licensed product provide free and open distribution for non-profit users, but requires a separate paid for commercial users. This is the case of MySQL database system. The non-commercial and free of charge license is GPL, and it takes advantage of the creativity of the open source community. The commercial license provides an enhanced version of the software (MySQL Pro), which is more secure and reliable. Consulting in OSS constitutes a different business model. In this case, a wide collection of open source packaged solutions is offered. Providing open software distributions and services is the chosen business model of companies like Red Hat, which constructs and sells software distributions rather than software products. In particular, Red Hat is specialised in creating and providing its own distributions of Linux, as well as providing extensive training, documentation, and support for its distributions. Hybrid proprietary and open models are also possible. The idea consists of taking open source software, applying it to a problem and selling the resulting solution. For instance, the development model of Google is oriented to the use of open source in general, although the final product is proprietary. In other cases, major companies support a corporate sponsorship for open source development. All these wide range of possibilities have in common the importance of firms' relationships with OSS communities. In some cases, firms found it necessary to change their business models to align with the communities. For instance, some firms needed to build a sufficiently large community to create a virtuous development cycle. However, the building and development of communities is not straightforward. Just establishing a community does not mean that individuals will necessarily be attracted to becoming 
members, or that their interest will be sustained over time (Dahlander and Magnusson, 2008). That is the reason why the relationship with communities is clearly an important aspect to take into account for managers (Toral et al., 2009c). Our study highlights the necessity of attracting new talents to keep the development of new functionalities and ideas, and of acquiring and retaining some degree of influence or control over future developments. Communities can be a valuable resource that a firm could leverage if it had relational capabilities (Bitzer and Schröder, 2006). In particular, a firm's capacity to manage and integrate a diverse range of actors within a network constitutes a distinctive capability, which can create a competitive advantage.

\section{Future research}

The current study is focused on a single virtual community, and its participation mechanism has been analysed from the perspective of the social network analysis. This analysis of community members' interactions has provided new insights about how the community can be managed to take advantage of collective innovation. Although the amount of research on the open source phenomenon has increased rapidly, it seems that this interest will grow in the near future attending to its magnitude. In this sense, further analyses of relationships with OSS communities represent a promising line of research (Toral et al., 2009b). For instance, the participation mechanism could be analysed in conjunction with community structure to derive some conclusions about the optimum organisation of the community. This study could also contribute to clarify the reasons successfully development of certain OSS projects.

As another future expansion of this work, the outcomes of the studied virtual community could be incorporated to the analysis using text categorisations tools such as latent semantic analysis (Shi and Malik, 2000), or latent dirichlet allocation (Blei et al., 2003). The idea would be to identify the addressed topics to measure not only the participation activities but also the shared content. In this way, the main dimensions related to knowledge sharing activities in virtual communities could be extracted.

Finally, the use of social tools and platforms in OSS projects could be studied to improve user interface and to increase the motivation of contributors.

\section{Conclusion}

Since two decades ago, Internet has promoted new kinds of software development to emerge. This upward trend has become more pronounced with the advent of Web 2.0 technologies. The new software development paradigm is based on virtual communities supporting both code generation and testing. Consequently, the success of the software will depend on the successful behaviour and evolution of the associated virtual community. In this paper, a successful virtual community has been analysed to conclude how they should be organised. Two contributions are provided. First, a methodology for virtual community analysis based on social network techniques is proposed. This methodology is focused on threads of discussion as the basic unit of analysis. Second, implications about the behaviour of successful virtual communities are obtained. These communities should be well structured and organised. The structure of the community should be based on the participation inequality principle, which leads to core/periphery topology where the role played by the core contributors is essential for the successful development of the project; and the maturity of core contributors and the hierarchy of the community should be accomplished as a community implementation previous task. 


\section{References}

Arakji, R.Y. and Lang, K.R. (2007), "The virtual cathedral and the virtual bazaar", ACM SIGMIS Database, Vol. 38 No. 4, pp. 32-9.

ARTEMIS Strategic Research Agenda Working Group (2006), Strategic Research Agenda, 1st ed., Ideo Ltd, London.

Barrero, F., Toral, S.L. and Gallardo, S. (2008), "eDSPLab: remote laboratory for experiments on DSP applications”, Internet Research, Vol. 18 No. 1, pp. 79-92.

Bird, C., Gourley, A., Devanbu, P., Gertz, M. and Swaminathan, A. (2006), "Mining e-mail social networks", Proceedings of the International Workshop on Mining Software Repositories, MSR'06, Shanghai, China, May 22-23, pp. 137-43.

Bitzer, J. and Schröder, P.J.H. (2006), The Economics of Open Source Software Development, Elsevier, Amsterdam.

Blei, D.M., Ng, A.Y. and Jordan, M.I. (2003), “Latent Dirichlet allocation”, Journal of Machine Learning Research, Vol. 3, pp. 993-1022.

Boland, R. and Tenkasi, R. (1995), "Perspective making and perspective taking in communities of knowing", Organization Science, Vol. 6 No. 4, pp. 350-72.

Borgatti, S.P. (2002), "NetDraw1.0”, Graph Visualization, Software, Analytic Technologies, Lexington, KY.

Borgatti, S.P. and Everett, M.G. (1999), "Models of core/periphery structures", Social Networks, Vol. 21, pp. 375-95.

Bovet, P.D. and Cesati, M. (2001), Understanding the Linux Kernel, O’Reilly, Sebastopol, CA.

Brown, J.S. and Duguid, P. (1998), "Organizing knowledge”, California Management Review, Vol. 40 No. 3, pp. 90-106.

Cusumano, M.A. (2008), "The changing software business: moving from products to services", Computer, Vol. 41 No. 1, pp. 20-7.

Dahlander, L. (2005), “Appropriation and appropriability in open source software”, International Journal of Innovation Management, Vol. 9 No. 3, pp. 259-85.

Dahlander, L. and Magnusson, M. (2008), "How do firms make use of open source communities?”, Long Range Planning, Vol. 41, pp. 629-49.

Deek, F.P. and McHugh, J.A.M. (2008), Open Source: Technology and Policy, Cambridge University Press, New York, NY.

Dixon, P.M., Weiner, J., Mitchell-Olds, T. and Woodley, R. (1987), "Bootstrapping the Gini coefficient of inequality", Ecology, Vol. 68, pp. 1548-51.

Figallo, C. (1998), Hosting Web Communities: Building Relationships, Increasing Customer Loyality, and Maintaining a Competitive Edge, Wiley Computer Publishing, Hoboken, NJ.

Fox, S. (2000), "Communities of practice, Foucault and actor-network theory", Journal of Management Studies, Vol. 37 No. 6, pp. 853-68.

Gini, C. (1936), On the Measure of Concentration with Especial Reference to Income and Wealth, Cowles Commission, New Haven, CT.

Gruber, M. and Henkel, J. (2006), "New ventures based on open innovation: an empirical analysis of start-up firms in embedded Linux", International Journal of Technology Management, Vol. 33 No. 4, pp. 356-72.

Healy, K. and Schussman, A. (2003), "The ecology of open-source software development", working paper, Department of Sociology, Social Sciences and University of Arizona, Tucson, AZ. 
Henkel, J. (2006), "Selective revealing in open innovation processes: the case of embedded Linux", Research Policy, Vol. 35 No. 7, pp. 953-69.

Hertel, G., Niedner, S. and Herrmann, S. (2003), "Motivation of software developers in open source projects: an Internet-based survey of contributors to the Linux kernel", Research Policy, Vol. 32 No. 7, pp. 1159-77.

Hummel, J. and Lechner, U. (2002), "Social profiles of virtual communities", Proceedings of the 35th Hawaii International Conference on System Sciences, IEEE Computer Society.

Jones, G., Ravid, G. and Rafaeli, S. (2004), "Information overload and the message dynamics of online interaction spaces: a theoretical model and empirical exploration", Information Systems Research, Vol. 15, pp. 194-210.

Knock, N. (2001), "Compensatory adaptation to a lean medium: an action research investigation of electronic communication in process involvement groups", IEEE Transactions on Professional Communication, Vol. 44 No. 4, pp. 267-85.

Kolbitsch, J. and Maurer, H. (2006), "The transformation of the web: how emerging communities shape the information we consume", Journal of Universal Computer Science, Vol. 12 No. 2, pp. 187-213.

Kuk, G. (2006), "Strategic interaction and knowledge sharing in the KDE developer mailing list", Management Science, Vol. 52 No. 7, pp. 1031-42.

Lakhani, K. and Hippel, E. (2003), "How open source software works: 'free' user to user assistance”, Research Policy, Vol. 32, pp. 923-43.

Lave, J., Wenger, E. and Pea, R. (1991), Situated Learning: Legitimate Peripheral Participation, Cambridge University Press, New York, NY.

Lee, G.K. and Cole, R.E. (2003), "From a firm-based to a community-based model of knowledge creation: the case of the Linux kernel development", Organization Science, Vol. 14 No. 6, pp. 633-49.

Lin, H.-F. (2007), "The role of online and offline features in sustaining virtual communities: an empirical study", Internet Research, Vol. 17 No. 2, pp. 119-38.

Madey, G., Freeh, V. and Tynan, R. (2004), "Modeling the F/OSS community: a quantitative investigation", in Koch, S. (Ed.), Free/Open Source Software Development, Idea Publishing, Hershey, PA, pp. 203-20.

Martínez-Torres, M.R. (2006), "A procedure to design a structural and measurement model of intellectual capital: an exploratory study”, Information and Management, Vol. 43 No. 5, pp. 617-26.

Millen, D., Feinberg, J. and Kerr, B. (2005), "Social bookmarking in the enterprise", ACM Queue, Vol. 3 No. 9, pp. 28-35.

Mockus, A., Fielding, R.T. and Herbsleb, J. (2000), "A case study of open source software development: the Apache server", Proceedings of the 22nd International Conference on Software Engineering, pp. 263-79.

Moody, G. (2001), Rebel Code: Linux and the Open Source Revolution, Perseus Press, Cambridge, MA.

Pan, S.L. and Leidner, D.E. (2003), "Bridging communities of practice with information technology in pursuit of global knowledge sharing", Journal of Strategic Information Systems, Vol. 12, pp. 71-88.

Raymond, E.S. (1999), “The cathedral and the bazaar”, available at: www.tuxedo.org/ esr/ writings/cathedral-bazaar/

Schwartz, D.G. and Te'eni, D. (2000), "Tying knowledge to action with k-mail”, IEEE Intelligent Systems, Vol. 15 No. 3, pp. 33-9. 
Shang, R.-A., Chen, Y.-C. and Liao, H.-J. (2006), "The value of participation in virtual consumer communities on brand loyalty", Internet Research, Vol. 16 No. 4, pp. 398-418.

Shi, J. and Malik, J. (2000), "Normalized cuts and image segmentation”, IEEE Trans. Pattern Analysis and Machine Intelligence, Vol. 22 No. 8, pp. 888-905.

Sowe, S., Stamelos, I. and Angelis, L. (2006), "Identifying knowledge brokers that yield software engineering knowledge in OSS projects", Information and Software Technology, Vol. 48, pp. 1025-33.

Te'eni, D. and Schwartz, D.G. (1999), "Contextualization in computer-mediated communication", in Brooks, L. and Kimble, C. (Eds), Information Systems - The Next Generation, McGraw-Hill, New York, NY, pp. 327-38.

Timmers, P. (1998), "Business models for electronic markets: EM - electronic markets", The International Journal of Electronic Markets and Business Media, Vol. 8 No. 2, pp. 3-8.

Toral, S.L., Martínez-Torres, M.R. and Barrero, F. (2009a), "Modelling mailing list behaviour in open source projects: the case of ARM embedded Linux", Journal of Universal Computer Science, Vol. 15 No. 3, pp. 648-64.

Toral, S.L., Martínez-Torres, M.R. and Barrero, F. (2009b), "Virtual communities as a resource for the development of OSS projects: the case of Linux ports to embedded processors", Behavior and Information Technology, Vol. 28 No. 5, pp. 405-19.

Toral, S.L., Martínez-Torres, M.R., Barrero, F. and Cortés, F.J. (2009c), "An empirical study of the driving forces behind online communities”, Internet Research, Vol. 19 No. 4, pp. 378-92.

Toral, S.L., Barrero, F., Martínez-Torres, M.R., Gallardo, S. and Lillo, J. (2005), "Implementation of a web-based educational tool for digital signal processing teaching using the technological acceptance model”, IEEE Transactions on Education, Vol. 48 No. 4, pp. 632-41.

Toral, S.L., Martínez-Torres, M.R., Barrero, F., Gallardo, S. and Durán, M.J. (2007), "An electronic engineering curriculum design based on concept-mapping techniques", International Journal of Technology and Design Education, Vol. 17 No. 3, pp. 341-56.

Waring, T. and Maddocks, P. (2005), "Open source software implementation in the UK public sector: evidence from the field and implications for the future", International Journal of Information Management, Vol. 25, pp. 411-28.

Weaver, A.C. and Morrison, B.B. (2008), "Social networking”, Computer, Vol. 41 No. 2, pp. 97-100.

Wenger, E. (1998), Communities-of-Practice: Learning, Meaning, and Identity, Cambridge University Press, Cambridge.

Wenger, E., McDermott, R. and Snyder, W.M. (2002), Cultivating Communities of Practice, Harvard Business School Press, Boston, MA.

Yaghmour, K. (2003), Building Embedded Linux Systems, O’Reilly, Sebastopol, CA.

\section{Corresponding author}

M.R. Martínez-Torres can be contacted at:rmtorres@us.es 